\title{
110 anos após a hipótese de Sutton-Boveri: a teoria cromossômica da herança é compreendida pelos estudantes brasileiros?
}

\author{
110 years after the Sutton-Boveri hypothesis: \\ is the chromosome theory of inheritance understood \\ by Brazilian students?
}

\author{
Felipe Domingos dos Santos ${ }^{1}$. Antonio Fernando Gouvea Silva ${ }^{2}$. \\ Fernando Faria Franco ${ }^{1}$
}

\begin{abstract}
Resumo: A Teoria Cromossômica da Herança (TCH), elaborada no início do século XX, consiste na proposição de que os fatores mendelianos estariam ligados aos cromossomos. Neste trabalho, foi realizada uma análise qualitativa sobre ensino-aprendizagem da TCH, envolvendo análise documental dos materiais didáticos e entrevistas semiestruturadas com discentes do Ensino Médio. Os resultados sugerem que os discentes não foram capazes de relacionar padrões de herança mendelianos com o processo de meiose. Com relação à análise documental, foi observada a dissociação dos conteúdos de Genética mendeliana dos de divisão celular meiótica. Uma proposta para superação dessa dificuldade seria trabalhar as bases epistemológicas da TCH usando a história da ciência. Essa proposta está fundamentada na ideia de que o contexto histórico-filosófico humaniza as ciências, podendo colaborar para a formação crítica do discente bem como para a aprendizagem significativa sobre a elaboração dos conceitos relacionados à temática estudada.
\end{abstract}

Palavras-chave: Teoria Cromossômica da Herança. Ensino de Genética. Ensino Médio.

\begin{abstract}
The Chromosomal Theory of Inheritance (TCI) developed in the early of twentieth century proposes that the Mendelian factors were linked to chromosomes. Here we performed a qualitative analysis on teaching and learning of the TCI, through the analysis of Biology textbooks and semi-structured interviews with high school students. The results suggest that students were not able to establish relationships between Mendelian inheritance and meiosis. Regarding the textbooks, we observed the clear dissociation of the contents between Mendel's laws and meiotic cell division. One way to overcome this difficulty would be a focus in the epistemology of the TCI using the history of science. This proposal has basis on the idea that historical and philosophical contexts can humanize the sciences and further may contribute to the critical formation of the student as well as support meaningful learning on the development of concepts related to the topic studied.
\end{abstract}

Keywords: Chromosomal Theory of Inheritance. Genetics teaching. High School.

\footnotetext{
${ }^{1}$ Departamento de Biologia, Centro de Ciências Humanas e Biológicas, Universidade Federal de São Carlos (UFSCar), Rodovia João Leme dos Santos SP264, KM110, CEP 18052-780, Sorocaba, SP, Brasil. E-mail:<franco@ufscar.br>.

${ }^{2}$ Departamento de Ciências Humanas e Educação, Centro de Ciências Humanas e Biológicas, Universidade Federal de São Carlos (UFSCar), Sorocaba, SP, Brasil.
} 


\section{Introdução}

Atualmente, a amplitude de conceitos relacionados ao ensino de Genética no Ensino Médio abrange as leis de Mendel e suas extensões, a análise de heredogramas, o estudo da ligação e mapeamento genético, as variações cromossômicas e determinação do sexo, além de outros conceitos básicos (FAVARETTO; MERCADANTE, 2005; LOPES; ROSSO, 2005). A despeito da abrangência de conceitos apresentada, o ensino de Genética parece falhar em fornecer subsídios básicos para o entendimento de questões gerais relacionadas à compreensão dos fenômenos biológicos envolvidos na transmissão das características hereditárias (BRANDÃO; FERREIRA, 2009; CID; NETO, 2005; LEWIS; LEACH; WOOD-ROBINSON, 2000; SANTOS; JOAQUIM; EL-HANI, 2012). Não há uma causa única para explicar este problema.

Uma questão inerente ao ensino de Genética, dada a escala microscópica do material genético, é o uso de um recurso pedagógico conhecido como analogia para ensinar, por exemplo, as leis mendelianas, em que os alelos e os cromossomos são geralmente representados por letras, como por exemplo: “X”, "Y”, “A”, “a”, "B” e "b”. Este recurso pedagógico, embora importante no processo de ensino-aprendizagem, muitas vezes pode prejudicar o entendimento acerca do fenômeno biológico estudado e o estabelecimento de relações com outras áreas dentro das Ciências Biológicas pelos discentes. Além disso, um dos problemas mais sérios no ensino e aprendizagem de Genética está relacionado à falta de compreensão dos processos celulares envolvidos na formação dos gametas em organismos sexuados (KLAUTAU-GUIMARÃES et al., 2011).

A relação entre a formação das células gaméticas e a segregação dos fatores mendelianos é assunto abordado pela Teoria Cromossômica da Herança (TCH), cuja compreensão é fundamental para o entendimento da hereditariedade. A TCH foi inicialmente contestada, sendo que diversos trabalhos posteriores à proposição da hipótese de que os fatores mendelianos estariam alocados nos cromossomos foram fundamentais para que a TCH fosse amplamente aceita (BENSON, 2001). O registro da construção do conhecimento científico acerca da TCH é amplo, fornecendo os diferentes pontos de vista e diversos conflitos dos cientistas sobre a base física da herança mendeliana. Esse registro pode ser utilizado no ensino das bases da hereditariedade, uma vez que a história da ciência é um recurso pedagógico informativo para o ensino de Biologia (CICILLINI, 1992; MARTINS, 1998) e, mais especificamente, Genética (SANTOS; JOAQUIM; EL-HANI, 2012; SCHEID; FERRARI, 2006).

Estudos empíricos para avaliar o ensino-aprendizagem da TCH não foram encontrados. O presente estudo teve como principal objetivo preencher essa lacuna avaliando os limites do processo de ensino-aprendizagem da TCH no Ensino Médio de uma escola brasileira, por meio de análise documental e entrevistas semiestruturadas.

\section{Breve histórico da Teoria Cromossômica da Herança}

Durante a segunda metade do século XIX, foram propostos diferentes modelos hipotéticos de herança de partículas microscópicas que explicariam a transmissão das características hereditárias dos organismos. Por exemplo: as unidades fisiológicas vivas de Hebert Spencer, a hipótese dos pangêneses de Charles Darwin, os pangêneses intracelulares de Hugo de Vries, e o 
plasma germinativo de August Weismann (LARSON, 2004; POLIZELLO, 2008; POLIZELLO; MARTINS, 2012). Particularmente o último modelo colocava um papel central do núcleo celular na hereditariedade, onde estava alocada a substância ácida "nucleína" descrita por Friederich Mischer (1871), e que posteriormente veio a ser denominada ácido nucléico (DAHM, 2005).

Também dentro desse contexto histórico está a publicação dos resultados dos experimentos do monge Gregor Johann $\mathrm{Mendel}^{3}$, cuja principal contribuição foi analisar matematicamente as proles híbridas resultantes de cruzamentos entre variedades de ervilhas (Pisum sativum), que serviram de subsídio para a proposição de um modelo microscópico de herança particulada (BRANDÃO; FERREIRA, 2009). Mendel elaborou dois princípios básicos da herança que ficaram conhecidos como Leis Mendelianas. Esses princípios foram publicados em 1866, mas seu significado foi amplamente apreciado em 1900, quando três botânicos interessados no estudo de hibridação de variedades - Hugo de Vries, Erich Von Tschemark e Carl Correns - começaram, independentemente, a chegar a conclusões semelhantes àquela de Mendel, chamando a atenção para seu trabalho pioneiro (STURTEVANT, 1965).

O princípio da segregação, tratado pela primeira Lei de Mendel, postula que cada indivíduo possui dois fatores hereditários ${ }^{4}$ para codificação de uma característica, sendo que estes fatores se segregam com igual probabilidade quando os gametas são formados. Outra contribuição de Mendel foi a elaboração do princípio da distribuição independente ou segunda Lei de Mendel. De acordo com esse princípio, os pares de fatores mendelianos para determinação de características diferentes se distribuem independentemente um dos outros na formação de gametas.

Embora o conhecimento da Genética mendeliana tenha sido extremamente importante para o entendimento da herança de características descontínuas, por meio dos diversos estudos envolvendo cruzamentos e análise de prole híbrida, que foram feitos na época da redescoberta dos trabalhos de Mendel, a base física e localização dos fatores mendelianos ainda permanecia desconhecida no início do século XX. Alguns geneticistas e defensores do mendelismo nessa época refutavam os fatores mendelianos como partículas materiais sobre os cromossomos, como havia sido especulado por pesquisadores importantes anteriormente à redescoberta dos trabalhos de Mendel, como Hugo de Vries e August Weismann, no final do século XIX (LARSON, 2004).

O estabelecimento da hipótese de que os cromossomos seriam a base física dos fatores mendelianos foi potencializado pelo desenvolvimento da Biologia Celular e aumento de conhecimento sobre as divisões celulares no final do século XIX e início do século XX, destacando-se os trabalhos desenvolvidos pelo grupo de pesquisa do professor Edmund Beecher Wilson, que esteve entre os primeiros a estudar embriologia experimentalmente (BENSON, 2001). Foi Walter Stanborough Sutton (SUTTON, 1902,1903) quem primeiro registrou a formulação da hipótese de que o comportamento dos cromossomos durante a meiose poderia explicar os padrões de segregação dos fatores mendelianos. Sutton iniciou seus estudos citológicos como aluno do Clarence Erwin McClung, mas foi como aluno de Wilson na Universidade de Columbia que

\footnotetext{
${ }^{3} \mathrm{O}$ trabalho original de Mendel Versuche über planzen-hybriden (traduzido do alemão como Experimentos de hibridação em plantas) foi publicado em um volume da Verhandlungen des naturforschenden vereines in Brünn, em 1866.

${ }^{4}$ Atualmente, tais fatores são denominados alelos (variantes de um mesmo gene). A descrição de que seriam dois fatores se justifica porque Mendel estudou um organismo diploide.
} 
interpretou seus dados de segregação cromossômica na meiose de uma espécie de gafanhoto (Brachystola magna), sob a luz do mendelismo (STURTEVANT, 1965).

A hipótese cromossômica da herança também é historicamente atribuída ao biólogo alemão Theodor Boveri (1862-1915), que, baseado em seus dados de meiose com espécies de ouriço-do-mar, forneceu estudos empíricos informativos sobre a continuidade estrutural do cromossomo e individualidade dos cromossomos ao longo das etapas das divisões celulares (LAUBICHLER; DAVIDSON, 2008). Pelo reconhecimento independente de que o comportamento dos fatores mendelianos durante a formação de gametas era exatamente paralelo ao comportamento dos cromossomos na meiose, a hipótese cromossômica da herança ficou conhecida como hipótese de Sutton-Boveri.

É importante salientar que, no período 1902-1903, não havia uma hipótese consensual sobre a associação de fatores mendelianos e os cromossomos, mas várias hipóteses diferentes e muitas vezes conflitantes (MARTINS, 1999). A hipótese de Suton-Boveri, no entanto, ganhou aceitação geral gradualmente, sendo inicialmente fortemente contestada, mesmo por Thomas Hunt Morgan, um dos pesquisadores que mais influenciaram para a posterior aceitação dessa hipótese por toda a comunidade científica, culminando no estabelecimento da Teoria Cromossômica da Herança (THC) (ARAÚJO; MARTINS, 2008; BENSON, 2001), que corresponde a um dos pressupostos básicos para a compreensão da hereditariedade.

Entre as principais dificuldades para a aceitação da hipótese cromossômica da herança, pode-se indicar a ausência de estudos associando fenótipos à herança de determinados cromossomos, e a necessidade de assumir que haveria muito mais fatores mendelianos do que cromossomos, o que sugeria, necessariamente, que alguns cromossomos poderiam estar relacionados a vários genes. Além disso, não havia nenhuma prova de que os lotes de cromossomos herdados dos genitores maternos e paternos, de fato, se segregariam independentemente, como requerido para explicar a segunda Lei de Mendel.

A relação entre um fenótipo específico e os cromossomos começou a ser estabelecida pela herança de cromossomos sexuais, quando McClung (1902) propôs que um então chamado cromossomo acessório (posteriormente, denominado X, devido a sua natureza e função incerta) estava envolvido na determinação do sexo em espécies de Hemiptera (STURTEVANT, 1965). Posteriormente, Nettie Stevens e Wilson corroboraram esses resultados e descreveram a relação dos cromossomos com a determinação do sexo para diversos grupos de insetos (STURTEVANT, 1965). No entanto, ainda existia a dúvida se essa associação entre cromossomos e um fenótipo específico estaria restrita à determinação do sexo (BENSON, 2001).

Com relação à segregação dos cromossomos, Carothers (1913) apresentou evidências experimentais de que os cromossomos se segregavam de forma independentemente. Trabalhando com McClung, essa pesquisadora encontrou, em uma espécie de Brachystola, uma configuração cromossômica que permitiu realizar esse teste. Nesta espécie, há um par de cromossomos homólogos heteromórfico em tamanho, bem com um cromossomo supranumerário. Ao estudar diversas placas meióticas dessa espécie, ela mediu que, em aproximadamente $50 \%$ das divisões, o cromossomo supranumerário migrava para o mesmo polo que o cromossomo maior do par heteromórfico; e, em outros $50 \%$, com o cromossomo menor, exatamente como seria esperado se a segregação fosse independente (CAROTHERS, 1913).

A partir de 1909, diversos trabalhos com a mosca Drosophila melanogaster, produzidos pelo grupo de Morgan, forneceram evidências que levaram ao estabelecimento da TCH (ARAÚJO; 
MARTINS, 2008). Esses trabalhos se concentravam no estudo de herança mendeliana em uma série de fenótipos como a cor dos olhos, o tamanho e a forma das asas nessas moscas. Dentre esses estudos, destacam-se as contribuições de Alfred Sturtevant, que, considerando o arranjo linear dos fatores mendelianos nos cromossomos, estabeleceu uma metodologia, baseada na frequência de prole recombinante, que poderia ser utilizada como uma medida quantitativa da distância desses fatores nos cromossomos (STURTEVANT, 1913). Ao conseguir êxito, além de permitir o estabelecimento dos primeiros mapas de ligação em Drosophila, a aplicação da metodologia proposta por Sturtevant também forneceu uma evidência indireta de que vários genes estariam, de fato, ligados a um mesmo cromossomo.

Embora Wilson e seus colaboradores tenham mostrado que a herança de alguns cromossomos estaria relacionada à determinação do sexo em insetos, foi com dados provenientes do estudo com Drosophila que se mostrou a relação direta entre genes ligados a determinados cromossomos e um fenótipo específico. $\mathrm{O}$ estudo da herança de um loco relacionado à cor dos olhos em Drosophila foi descrito por Morgan como associado ao cromossomo X, devido à proporção de prole masculina e feminina encontrada com o fenótipo recessivo (cor branca) e dominante (cor vermelha), obtida a partir de uma série de cruzamentos recíprocos envolvendo parentais com a cor dos olhos brancos cruzados com os de olhos vermelhos (STURTEVANT, 1965). Posteriormente, Bridges (1913) apresentou um estudo mostrando que, a partir de um cruzamento de uma fêmea de olhos brancos (homozigota recessiva) com um macho de olhos vermelhos (hemizigoto dominante), uma proporção pequena da prole masculina e feminina apresentava olhos vermelhos e brancos, respectivamente, ao contrário do que seria esperado. A explicação dada por Bridges, e confirmada citologicamente, foi a de que eventos de nãodisjunção de cromossomos sexuais $\mathrm{X}$ nos ovócitos femininos durante a meiose, formando parte dos gametas com duas cópias do X carregando o alelo mutante e parte dos gametas sem nenhum cromossomo X, poderiam levar à formação de indivíduos aneuploides XXY (fêmea fenotípica com olhos brancos) e X0 (machos fenotípicos com olhos vermelhos), respectivamente (STURTEVANT, 1965). Esse estudo forneceu uma forte evidência de que os fatores genéticos estariam ligados aos cromossomos.

Como um dos marcos relacionado ao estabelecimento da TCH, está a publicação, em 1915, da obra The mechanism of Mendelian heredity, de Morgan e colaboradores, em que todas as evidências acumuladas sobre essa teoria estavam compiladas. As inconsistências em relação a alguns aspectos da TCH ainda existentes na época da publicação dessa obra foram superadas nos anos subsequentes, como, por exemplo, por meio da descrição de evidências citológicas do crossing-over e estabelecimento de ferramentas matemáticas para o cálculo de distância entre fatores na construção de mapas cromossômicos, de modo que, por volta de 1930, havia um corpo sólido de evidências favoráveis à TCH (ARAÚJO; MARTINS, 2008).

Posteriormente, uma série de estudos culminou na descrição da estrutura da molécula de DNA, da estrutura molecular dos genes e da associação do DNA com proteínas histonas na formação dos cromossomos, corroborando com a TCH. Além disso, também foi descrito que existe material genético em duas organelas citoplasmáticas, a mitocôndria e o cloroplasto. Esse fato não abala a concepção inicial de que os fatores mendelianos estão ligados aos cromossomos, uma vez que essas organelas celulares exibem um padrão de herança não mendeliano, constituindo uma das extensões do mendelismo atualmente reconhecida. 


\section{Metodologia}

A pesquisa foi desenvolvida em uma instituição de Ensino Médio da rede de Educação Básica do município de Sorocaba, Estado de São Paulo, Brasil. Inicialmente, foram realizadas observações em sala de aula, em diversas turmas, ao longo da disciplina "Biologia", durante o $2^{\circ}$ semestre de 2010 e o $1^{\circ}$ semestre de 2011 (cento e oitenta horas), para identificar como as aulas nesta disciplina são abordadas e como os conteúdos para o ensino de Genética são tratados pelos educadores.

Posteriormente, foi realizada uma pesquisa qualitativa com a finalidade de identificar a compreensão dos alunos acerca dos conteúdos adotados no ensino de Genética. Neste tipo de abordagem, o problema é analisado no ambiente em que ele naturalmente ocorre, envolvendo a obtenção de dados descritivos a partir do contato direto do pesquisador com a situação analisada (BOGDAN; BIKLEN, 1982; STUBBS; DELAMONT, 1976).

Foram realizadas entrevistas semiestruturadas em que o pesquisador predetermina tópicos relacionados ao tema de estudo que nortearão a entrevista, mas que não serão, necessariamente, respondidas pelos entrevistados (BONI; QUARESMA, 2005). A perspectiva é facilitar a discussão sobre o tema sem que a entrevista se torne intimidadora, permitindo, aos entrevistados, maior espontaneidade em suas respostas.

Os tópicos norteadores das entrevistas abertas ${ }^{5}$ com educandos envolveram a compreensão dos aspectos biológicos relacionados à hereditariedade, bem como o ensino-aprendizagem da mesma. Os principais tópicos foram: princípios de hereditariedade, hereditariedade e transmissão de características, princípios sobre divisão celular, o mecanismo e a ocorrência da divisão celular, hereditariedade e as divisões celulares. As entrevistas foram realizadas em cinco encontros (eventos) envolvendo grupos distintos de alunos do Ensino Médio ${ }^{6}$.

Em termos documentais, também foram pesquisados os livros didáticos de Favaretto e Mercadante (2005) e Lopes e Rosso (2005). Tais obras são do Programa Nacional do Livro Didático para o Ensino Médio (PNLEM), e são adotados na instituição de Ensino Médio em que a pesquisa foi desenvolvida. A análise concentrou-se nos princípios básicos de divisões celulares e leis mendelianas, dando atenção à estruturação dos conteúdos, às inter-relações e à distribuição dos conceitos envolvidos na TCH.

\section{Resultados}

Na prática docente dos professores de Biologia, não foi observada nenhuma menção sobre a TCH. Considerando a análise documental, o livro de Favaretto e Mercadante (2005) é

\footnotetext{
${ }^{5}$ Todas as entrevistas tinham um roteiro norteador - construído a partir de equívocos recorrentes na aprendizagem da área encontrados na pesquisa bibliográfica previamente realizada - que sofreu modificações em função do desenvolvimento da coleta de dados de acordo com as respostas dos entrevistados. Tal roteiro envolvia questões relacionadas às concepções dos educandos em relação aos princípios básicos de herança, da gametogênese e inter-relação entre a segregação dos cromossomos na meiose e a dos alelos.

${ }^{6} \mathrm{Um}$ total de 14 alunos participou dos eventos de entrevistas, sendo dois, um, dois, três e seis discentes entrevistados nos eventos de 1 a 5 , respectivamente.
} 
subdividido em três seções, sendo elas: $O$ cenário da vida, $A$ unidade da vida e $A$ diversidade da vida. Embora os conceitos sobre Biologia Celular e Genética tenham sido apresentados na segunda seção desse livro, nenhuma relação entre essas duas subdisciplinas da biologia foi estabelecida, e em nenhum capítulo do livro foi observada alguma menção a TCH (Quadro 1). O livro publicado por Lopes e Rosso (2005) apresenta sete seções, onde o conteúdo referente à Biologia Celular se encontra unicamente na seção sobre Citologia, enquanto o capítulo de Genética em outra seção. Neste livro, no entanto, a TCH foi mencionada de forma sucinta, com abordagem descritiva (Quadro 1).

Quadro 1. Representação resumida dos dados obtidos de acordo com a análise documental dos materiais didáticos envolvidos no processo de ensino-aprendizagem da instituição de ensino (2010).

\begin{tabular}{|c|l|l|l|l|}
\hline & $\begin{array}{c}\text { Organização do } \\
\text { material didático }\end{array}$ & $\begin{array}{c}\text { Disposição dos } \\
\text { conteúdos de Citologia } \\
\text { e Genética }\end{array}$ & $\begin{array}{c}\text { Relação entre } \\
\text { Citologia e } \\
\text { Genética pela TCH }\end{array}$ & $\begin{array}{c}\text { Ação e } \\
\text { Prática } \\
\text { Docente }\end{array}$ \\
\hline $\begin{array}{c}\text { Favaretto; } \\
\text { Mercadante } \\
(2005)\end{array}$ & $\begin{array}{l}\text { Três seções: O } \\
\text { cenário da vida, a } \\
\text { unidade da vida e a } \\
\text { diversidade da vida }\end{array}$ & $\begin{array}{l}\text { Os conteúdos estão } \\
\text { presentes em capítulos } \\
\text { diferentes da mesma seção. }\end{array}$ & $\begin{array}{l}\text { Nenhuma menção a } \\
\text { TCH }\end{array}$ & $\begin{array}{l}\text { Sem } \\
\text { integração } \\
\text { dos } \\
\text { conteúdos }\end{array}$ \\
\hline $\begin{array}{c}\text { Lopes; } \\
\text { Rosso (2005) }\end{array}$ & $\begin{array}{l}\text { Sete seções, dentre } \\
\text { elas: Citologia e } \\
\text { Genética }\end{array}$ & $\begin{array}{l}\text { Os conteúdos estão } \\
\text { alocados em seções } \\
\text { diferentes }\end{array}$ & $\begin{array}{l}\text { TCH apresentada de } \\
\text { maneira descritiva }\end{array}$ & $\begin{array}{l}\text { Sem } \\
\text { integração } \\
\text { dos } \\
\text { conteúdos }\end{array}$ \\
\hline
\end{tabular}

Fonte: Elaborado pelos autores.

Com relação às entrevistas semiestruturadas, foram estabelecidos os critérios de classificação em: "satisfatório", "regular" e "insatisfatório", para quantificar o entendimento dos alunos acerca dos principais tópicos relacionados à hereditariedade (Quadro 2). Ainda no Quadro 2, são apresentados os resultados sobre a investigação do reconhecimento dos discentes em relação aos seguintes aspectos: conhecimentos fundamentais sobre herança, como, por exemplo, que a prole se assemelha mais com os seus genitores do que com os demais membros da população; aspectos de passagem de características de uma geração a outra, sendo necessário conhecer os princípios de herança mendeliana e compreender o processo de segregação dos cromossomos; a compreensão sobre a variabilidade Genética a partir da ação de segregação, que permite a diferenciação entre genitores e a prole, por exemplo; a compreensão das diferenças e semelhanças funcionais nas divisões celulares da mitose e meiose; e se os entrevistados compreendiam que as divisões celulares estavam inteiramente relacionadas com a transmissão de características de uma geração a outra. 
Quadro 2. Representação resumida dos dados obtidos de acordo com os eventos de entrevistas semiestruturadas, para exploração dos principais temas que envolvem a observação dos conteúdos acerca da Teoria Cromossômica da Herança (2011).

\begin{tabular}{|l|c|c|c|c|c|}
\hline & $\begin{array}{c}\text { Noções } \\
\text { fundamentais de } \\
\text { hereditariedade }\end{array}$ & $\begin{array}{c}\text { Hereditariedade } \\
\text { e transmissão de } \\
\text { características }\end{array}$ & $\begin{array}{c}\text { Princípios } \\
\text { sobre divisão } \\
\text { celular }\end{array}$ & $\begin{array}{c}\text { O processo de } \\
\text { ocorrência das } \\
\text { divisões celulares }\end{array}$ & $\begin{array}{c}\text { Hereditariedade } \\
\text { e as divisões } \\
\text { celulares }\end{array}$ \\
\hline Evento 1 & $\mathrm{S}^{(i)}$ & $\mathrm{R}^{(i)}$ & $\mathrm{R}$ & $\mathrm{I}$ & $\mathrm{I}$ \\
\hline Evento 2 & $\mathrm{R}$ & $\mathrm{R}$ & $\mathrm{R}$ & $\mathrm{I}$ & $\mathrm{I}$ \\
\hline Evento 3 & $\mathrm{R}$ & $\mathrm{R}$ & $\mathrm{R}$ & $\mathrm{I}$ & $\mathrm{I}$ \\
\hline Evento 4 & $\mathrm{S}$ & $\mathrm{S}$ & $\mathrm{R}$ & $\mathrm{R}$ & $\mathrm{I}$ \\
\hline Evento 5 & $\mathrm{S}$ & $\mathrm{S}$ & $\mathrm{R}$ & $\mathrm{R}$ & $\mathrm{I}$ \\
\hline
\end{tabular}

(i) $\mathrm{S}$ - Satisfatório, quando há relações entre conceitos básicos; ${ }^{\text {(i) }} \mathrm{R}$ - Regular, quando há uma resolução acerca do conteúdo tratado, sem relações ou associações concretas; e ${ }^{(i i)} \mathrm{I}$ - Insatisfatório, quando não há compreensão tanto dos princípios básicos quanto de possíveis relações.

Fonte: Elaborado pelos autores.

\section{Discussão}

A pesquisa qualitativa apresentada nesse trabalho sugere que, embora os alunos tenham apresentado o conhecimento de conceitos básicos de Genética e Biologia Celular, eles não foram capazes de estabelecer relações básicas entre conteúdos que são fundamentais para o aprendizado significativo da hereditariedade (Quadro 2). Nós consideramos que essa dificuldade pode estar relacionada à falta de eixos integradores entre diferentes disciplinas das Ciências Biológicas, com a organização dos conteúdos nos materiais didáticos agregada ao resgate do processo de produção da ciência, ou, mesmo, com a integração destes conteúdos na prática docente (Quadro 1), como, por exemplo, com o uso de História da Ciência (CICILLINI, 1992).

No Brasil, os Parâmetros Curriculares Nacionais do Ensino Médio (PCNEM), um documento elaborado pelo Ministério da Educação do Governo Federal, orienta a adequação dos conteúdos de Biologia ao currículo escolar (BRASIL, 1999). No caso da Genética, existe uma série de conteúdos propostos como essenciais para o seu entendimento, que incluem fundamentos de matemática e estatística, mas, essencialmente, de Biologia Celular (KLAUTAUGUIMARÃES et al., 2011). Nesse sentido, a falta de integração entre as disciplinas de Genética e Biologia Celular na sala de aula pode ser reflexo da fragmentação de tais disciplinas nos livros didáticos, que, muitas vezes, são a principal ou, mesmo, a única fonte de consulta e estudo para os discentes e docentes (VERCEZE; SILVINO, 2008), sendo, portanto, um potencial replicador de problemas no processo de ensino-aprendizagem (MELO; CARMO, 2009).

De acordo com os PCNEM, deve ser articulado o envolvimento dos conteúdos de modo a tornar clara a compreensão da transmissão hereditária de características. Ao se abordar sobre o tema, coloca-se uma especificidade ao caráter de se utilizarem apenas as leis de Mendel e conceitos correlatos, como os alelos múltiplos, recombinação gênica, herança quantitativa e herança ligada ao sexo: 
É preciso que o aluno relacione os conceitos e processos acima expressos, nos estudos sobre as leis da herança mendeliana e algumas de suas derivações, como alelos múltiplos, herança quantitativa e herança ligada ao sexo, recombinação gênica e ligação fatorial. (BRASIL, 1999, p. 19)

Entretanto, se houver uma integração conceitual com aspectos das Ciências e associá -los aos conceitos de hereditariedade, acreditamos que se torna possível uma ponte integradora para a compreensão completa dos processos biológicos na transmissão de características. No caso da Genética, sem conhecer a base física dos fatores mendelianos torna-se difícil para os discentes compreenderem as leis mendelianas, sendo que, muitas vezes, o ensino dessa disciplina no Ensino Médio é feito de uma forma linear e sem contextualização histórica, se resumindo à memorização de regras e segregação de símbolos que representam alelos (SANTOS; JOAQUIM; EL-HANI, 2012). Neste contexto, para um aprendizado significativo em Genética, é fundamental entender as bases da segregação cromossômica, incorporando, para isso, a Biologia Celular, e apresentando, aos discentes, que os padrões de segregação mendeliana são reflexos da segregação desses cromossomos.

Uma alternativa de superação para o diagnóstico apresentado neste trabalho inclui uma melhor organização de conteúdos em materiais didáticos, que forneça um eixo integrado entre diferentes disciplinas das Ciências Biológicas, e, assim, favoreça uma prática docente que torne possível a construção do conhecimento científico na abordagem dos conteúdos. Dentro dessa perspectiva, os PCNEM abordam a importância do âmbito histórico-filosófico, nas Ciências, na definição e contextualização dos conteúdos curriculares básicos, e que pode ser usado como base, se incorporado ao currículo, para a superação dos limites da compreensão da hereditariedade:

Não é possível tratar, no Ensino Médio, de todo o conhecimento biológico ou de todo o conhecimento tecnológico a ele associado. Mais importante é tratar esses conhecimentos de forma contextualizada, revelando como e por que foram produzidos, em que época, apresentando a história da Biologia como um movimento não linear e frequentemente contraditório. (BRASIL, 1999, p. 19)

Atualmente, a TCH é tratada como apenas mais um conteúdo comum, quando a mesma é abordada no Ensino Médio. Nós consideramos que essa teoria, se aplicada dentro de uma contextualização histórica, tem potencial para integrar disciplinas relacionadas à hereditariedade, no sentido em que, ao se compreender a TCH, torna-se natural o entendimento de outros conteúdos da Genética, tais como: extensões do mendelismo, ligação, aneuploidia e poliploidia. Em uma cadeia de eventos, ao se entenderem as bases genéticas da herança, é possível uma melhor compreensão da teoria evolutiva, que é o eixo integrador das Ciências Biológicas, favorecendo o entendimento da Biologia como um todo (TIDON; LEWONTIN, 2004).

Evidentemente, para tanto, é necessária uma reflexão sobre a formação inicial e permanente do docente na organização e seleção dos conteúdos inseridos no currículo, para que a História da Ciência não seja usada de maneira ingênua ou como uma sequência linear de fatos, impedindo a formação de uma concepção crítica sobre a temática (MARTINS, 1998; SANTOS; JOAQUIM; EL-HANI, 2012). 
A TCH é um dos exemplos bem documentados de discussões conceituais na comunidade científica, entre pontos de vista discordantes de que os fatores hereditários estariam exclusivamente associados ao citoplasma ou ao núcleo celular (BENSON, 2001; MARTINS, 1999). A proposição das ideias de Sutton $(1902,1903)$ promoveu a discussão de diversos pontos conflitantes sobre os pressupostos da base física dos fatores mendelianos. Dentre esses pontos, estão incluídos temas fundamentais relacionados aos conteúdos do currículo de Genética, e que podem ser abordados em sala de aula em uma contextualização histórica, como: segregação independente, crossing-over, ligação e não-disjunção meiótica, apenas para citar alguns exemplos. Outra vantagem da utilização da contextualização histórica da TCH é que a literatura sobre a proposição e posterior aceitação dessa teoria é vasta, fornecendo, aos educadores e educandos, diferentes fontes de consulta e diferentes olhares sobre um mesmo tema.

Ao se explorarem os contextos históricos e se refletir sobre eles, é possível compreender melhor como o conhecimento científico é produzido no presente e como ele foi debatido no passado. Além disso, permite, também, comprometer-nos com as situações de acordo com a época que ocorreram os fatos e desenvolvermos planos para o ensino e aprendizagem de acordo com esse contexto (CARNEIRO; GASTAL, 2005; DUARTE, 2004).

Com a discussão de propostas que abordam os contextos históricos e sociais da Ciência, são formuladas ideias que norteiam e baseiam todo o campo de estudo, de modo a se compreender como o conteúdo científico foi estabelecido; e, de acordo com a época em questão, favorecendo e auxiliando no desenvolvimento e no caminho que levarão à construção do conhecimento entre os pesquisadores e a sociedade. Além disso, essa abordagem permite a desmistificação em torno da figura do cientista, muitas vezes visto como uma figura excêntrica e que não é passível de erros, além de permitir que o educando perceba que suas dúvidas são cabíveis em relação aos conceitos que demoraram tanto tempo para serem estabelecidos (MARTINS, 1998).

Em síntese, a utilização de uma contextualização histórica no ensino, ao mesmo tempo em que informa, humaniza as ciências, permitindo a reflexão dos estudantes sobre como os conceitos são estabelecidos e como eles podem ser modificados ao longo do tempo e serem reinterpretados. Essa abordagem se alinha com diferentes autores que ressaltam a importância da História da Ciência como um recurso pedagógico eficiente para o ensino de Ciências e Biologia (ALMEIDA, 2004; CARNEIRO; GASTAL, 2005; CICILLINI, 1992; MARTINS, 1998; SCHEID; FERRARI, 2006). 
110 anos após a hipótese de Sutton-Boveri: ...

\section{Referências}

ALMEIDA, M. J. P. M. Historicidade e interdiscurso: pensando a educação em ciências na escola básica. Ciência \& Educação, Bauru, v. 10, n. 3, p. 333-341, 2004. Disponível em: <http://dx.doi.org/10.1590/S1516-73132004000300003>. Acesso em: 21 ago. 2015.

ARAÚJO, A. M.; MARTINS, L. A-C. P. A teoria cromossômica da herança e a teoria do plastinema de Toledo Piza Jr.: um confronto esquecido. Filosofia e História da Biologia, São Paulo, v. 3, p. 1-19, 2008. Disponível em: <http:/ /www.abfhib.org/FHB/FHB-03/FHBv03-01-Aldo-Araujo-Lilian-Martins.pdf>. Acesso em: 21 ago. 2015.

BENSON, K. R. T. H. Morgan's resistance to the chromosome theory. Nature Reviews Genetics, London, v. 2, p. 469-474, 2001.

BOGDAN, R.; BIKLEN, S. K. Qualitative reserch for education: an introduction for to theory and methods. Boston: Allyn and Bacon, 1982.

BONI, V.; QUARESMA, S. J. Aprendendo a entrevistar: como fazer entrevistas em ciências sociais. Em Tese: revista eletrônica dos pós-graduandos em sociologia política da UFSC, Florianópolis, v. 2, n. 1, p. 68-80, 2005. Disponível em: <https://periodicos.ufsc.br/index. php/emtese/article/view/18027/16976>. Acesso em: 21 ago. 2015.

BRANDÃO, G. O.; FERREIRA, L. B. M. O ensino de Genética no nível médio: a importância da contextualização histórica dos experimentos de Mendel para o raciocínio sobre os mecanismos da hereditariedade. Filosofia e História da Biologia, São Paulo, v. 4, p. 43-63, 2009. Disponível em: < http://www.abfhib.org/FHB/FHB-04/FHB-v04-02Gilberto-Brandao-Louise-Ferreira.pdf>. Acesso em: 21 ago. 2015.

BRASIL. Ministério da Educação. Parâmetros curriculares nacionais: ensino médio. Brasília, 1999.

BRIDGES, C. B. Non-disjunction of the sex chromosomes of Drosophila. Journal of Experimental Zoology, Hoboken, v. 15, n. 4, p. 587-606, 1913.

CARNEIRO, M. H. S.; GASTAL, M. L. História e filosofia das ciências no ensino de biologia. Ciência \& Educação, Bauru, v. 11, n. 1, p. 33-39, 2005. Disponível em: < http:// www.scielo.br/pdf/ciedu/v11n1/03.pdf>. Acesso em: 21 ago. 2015.

CAROTHERS, E. E. The mendelian ratio in relation to certain orthopteran chromosomes. Journal of Morphology, Hoboken, v. 24, n. 4, p. 487-511, 1913.

CICILLINI, G. A. A história da ciência e o ensino de biologia. Ensino em Re-vista, Uberlândia, v. 1, n. 1, p. 7-14, 1992. Disponível em: <http://www.seer.ufu.br/index.php/ emrevista/article/view/7746/4876>. Acesso em: 21 ago. 2015.

CID, M.; NETO, A. J. Dificuldades de aprendizagem e conhecimento pedagógico do conteúdo: o caso da Genética. Enseñanza de las Ciencias, Barcelona, p. 1-5, 2005. Número extra. Disponível em: < http://ddd.uab.cat/pub/edlc/edlc_a2005nEXTRA/edlc_ a2005nEXTRAp270difapr.pdf>. Acesso em: 21 ago. 2015. 
DAHM, R. Friedrich Miescher and the discovery of DNA. Developmental Biology, Maryland Heights, v. 278, n. 2, p. 274-288, 2005.

DUARTE, M. C. A história da ciência na prática de professores portugueses: implicações para a formação de professores de ciências. Ciência \& Educação, Bauru, v. 10, n. 3, p. 317-331, 2004. Disponível em: <http://dx.doi.org/10.1590/S1516-73132004000300002>. Acesso em: 21 ago. 2015.

FAVARETTO, J. A.; MERCADANTE, C. Biologia: volume único. São Paulo: Moderna, 2005.

KLAUTAU-GUIMARÃES, M. N. et al. Entendendo a variação genética. Genética na Escola, Ribeirão Preto, v. 6, n. 1, p. 56-66, 2011.

LARSON, E. J. Evolution: the remarkable history of a scientific theory. New York: Modern Library, 2004.

LAUBICHLER, M. D.; DAVIDSON, E. H. Boveri's long experiment: sea urchin merogones and the establishment of the role of nuclear chromosomes in development. Developmental Biology, Maryland Heights, v. 314, n. 1, p 1-11, 2008.

LEWIS, J.; LEACH, J.; WOOD-ROBINSON, C. What's a cell?: young people's understanding of the genetic relationship between cells, within an individual. Journal of Biological Education, Philadelphia, v. 34, n. 3, p. 129-132, 2000.

LOPES, S.; ROSSO, S. Biologia: volume único. São Paulo: Saraiva, 2005.

MARTINS, L. A-C. Did Sutton and Boveri propose the so-called Sutton-Boveri chromosome hypothesis? Genetics and Molecular Biology, São Paulo, v. 22, n. 2, p. 261-271, 1999. Disponível em: <http://dx.doi.org/10.1590/S1415-47571999000200022>. Acesso em: 21 ago. 2015.

. A história da ciência e o ensino de biologia. Ciência \& Ensino, Campinas, n. 5, p 18-21, 1998. Disponível em: < http://www.educadores.diaadia.pr.gov.br/arquivos/File/ fevereiro2013/ciencias_artigos/historia_ciencia.pdf>. Acesso em: 21 ago. 2015.

McCLUNG, C. E. The accessory chromosome - sex determinant? Biological Bulletin, Woods Hole, v. 3, p. 43-84, 1902. Disponível em: <http://davinci.nhm.ku.edu/foundations/ genetics/classical/cem-02.pdf>. Acesso em: 21 ago. 2015.

MELO, J. R.; CARMO, E. M. Investigações sobre o ensino de Genética e biologia molecular no ensino médio brasileiro: reflexões sobre as publicações científicas. Ciência \& Educação, Bauru, v. 15, n. 3, p. 593-611, 2009. Disponível em: < http://dx.doi.org/10.1590/S1516$73132009000300009>$. Acesso em: 21 ago. 2015.

POLIZELLO, A. Modelos microscópicos de herança no século XIX: a teoria das estirpes de Francis Galton. Filosofia e História da Biologia, São Paulo, v. 3, p. 41-54, 2008. Disponível em: < http://www.abfhib.org/FHB/FHB-03/FHB-v03-03-Andreza-Polizello.pdf > . Acesso em: 26 ago. 2015. 
POLIZELLO, A.; MARTINS, L. A-C. P. Modelos microscópicos de herança no século XIX. Filosofia e História da Biologia, v. 7, n. 2, p. 137-155, 2012. Disponível em: <http:// www.abfhib.org/FHB/FHB-07-2/FHB-7-2-01-Andreza-Polizello_Lilian-Al-Chueyr-PereiraMartins.pdf >. Acesso em: 26 ago. 2015.

SANTOS, V. C.; JOAQUIM, L. M.; EL-HANI, C. N. Hybrid deterministic views about genes in biology textbooks: a key problem in genetics teaching. Science \& Education, Hoboken, v. 21 , n. 4 , p. 543-578, 2012.

SCHEID, N. M. J.; FERRARI, N. A história da ciência como aliada no ensino de Genética. Genética na Escola, Ribeirão Preto, v. 1, n. 1, p. 17-18, 2006. Disponível em: <http://www. educadores.diaadia.pr.gov.br/arquivos/File/fevereiro2013/ciencias_artigos/historia_ciencia_ genetica.pdf>. Acesso em: 26 ago. 2015.

STUBBS, M.; DELAMONT, S. (Org.). Explorations in classroom observation. London: John Wiley, 1976.

STURTEVANT, A. H. A history of genetics. New York: Harper \& Row, 1965.

. The linear arrangement of six sex-linked factors in Drosophila, as shown by their mode of association. Journal of Experimental Zoology, Hoboken, v. 14, n. 1, p. 43-59, 1913.

SUTTON, W. S. The chromosomes in heredity. Biological Bulletin,Woods Hole, v. 4, p. 231-251, 1903. Disponível em: < http://ai.stanford.edu/ serafim/CS374_2004/Papers/ Chromosome.pdf $>$. Acesso em: 26 ago. 2015.

. On the morphology of the chromosome group in Brachystola magna. Biological Bulletin, Woods Hole, v. 4, p. 24-39, 1902. Disponível em: <http:/ /www.biolbull.org/ content/4/1/24.full.pdf>. Acesso em: 26 ago. 2015.

TIDON, R.; LEWONTIN, R. C. Teaching evolutionary biology. Genetics and Molecular Biology, Ribeirão Preto, v. 27, n. 1, p. 124-131, 2004. Disponível em: <http://dx.doi. org/10.1590/S1415-47572004000100021>. Acesso em: 26 ago. 2015.

VERCEZE, R. M. A. N.; SILVINO, E. F. M. O livro didático e suas implicações na prática do professor nas escolas públicas de Guajará-Mirim. Revista Teoria e Prática da Educação, Maringá, v. 11, n. 3, p. 338-347, 2008. Disponível em: < http:/ /www.dtp.uem.br/ rtpe/volumes/v11n3/010_rosa-338-347.pdf>. Acesso em: 26 ago. 2015. 